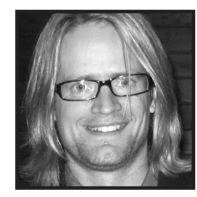

\title{
The Teacher as Silenced Superhero
}

\author{
Sean Wiebe, University of Prince Edward Island
}

\begin{abstract}
In this essay I argue that social ideals create an imaginary that inspires self-discipline in beliefs, thinking, and practices in order to achieve social-utopian hopes that the world will improve in particular ways. As such, social ideals limit human agency in general, and, for teachers in particular, there is limited terrain in which they have the right to speak. As a substitute for their right to speak, I argue, teachers are given the token social status of superhero, a fantasy consistent with neoliberal styles of thought. Following Pinar's notion of art-as-event, I propose that deep engagement in the arts might be a means of restoring agency and voice to teachers; I argue that art troubles the strong socialization motif in education and creates intellectual room for the development of genuinely educational moments in schooling.
\end{abstract}

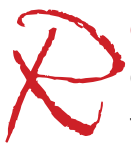
eferring to teachers generally and to a social imaginary that makes heroes of them, Block (2014) posits a representative teacher who is "constrained to be silent, though she must speak" (p. 31). Having studied teacher voice and agency (Wiebe \& Gard, in press; Wiebe \& MacDonald, 2014; Wiebe \& MacDonald, 2013), particularly in relation to the workload and worklife conditions of teachers on Prince Edward Island (MacDonald, Wiebe, Goslin, Doiron, \& MacDonald, 2010), I can attest to the irony of teachers holding inside themselves an urgent imperative to speak, but being prevented from doing so. Locating my work in both the arts and curriculum studies, I consider the phenomenon of a speaking subject one of my chief concerns, particularly given the present that puts such a possibility at risk.

Later in his paper, Block (2014) reveals what he believes to be an underlying cause of what silences teachers-we make heroes of them. His description of the social imaginary convening heroic status on teachers is apt: 
In the eyes of society I have become in some odd way rendered superhumanly responsible for the current and future state of the whole country, at least. I have learned that this is my state because the description and directive appears daily in the newspapers. They - the politicians and pundits-say that my effort should result in a recovered world, a redeemed world. They say, my work should be such as to raise the dead. (p. 35)

While it seems like an act of support to make heroes of our teachers, it is a fantasy that forecloses on their ability to speak. Idealism creates projections and expectations that limit the range of possible human activity. Pinar (2010) explains, "Even a lovely objective is an objective nonetheless, which commits one to acting toward its realization, i.e., instrumentally. This is where things get ugly, as we must reduce the present to its function in achieving the planned future" (p. 3). With a picture of what could be better, the ideal marginalizes any activity that is not a function of attaining it, reducing the experience of life to an instrumental do-this-to-achieve-that. Idealism diminishes the value of the present, and, by extension, the human being's value in speaking. Writ large, when social institutions pursue ideals, engage in development practices to achieve them, and ensure progress through regulations and measurements, you can be sure that expressions of difference, whether verbal or communicated in some other way, will be unwelcome enough to require discipline.

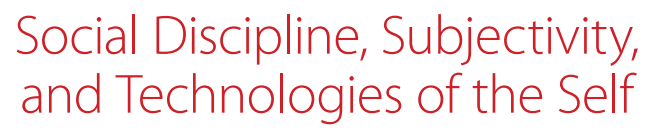

Social discipline need not be formal and most often functions as part of the habits and routines that are normalized as part of institutional life. To explain how prevailing understandings can be natively situated in languages, practices, and shared beliefs, Nicholas Ng-A-Fook (2014) has recently taken up Taylor's (1989) notion of the social imaginary, making the connection to Canadian curriculum studies through Pinar's (2008) re-invigoration of the phrase common countenance. "Such common countenance," Ng-A-Fook says, "can create blinders" (p. 103) for those working in education. Panayotidis, Towers, Lund, and Smits (2015) refer to this commonness as "a taken-for-grantedness" one they endeavor to struggle against in the hope that "things can be other than they are" (p. 37). Digging deeper, they note that the difficulty is one of imagination since the challenge before them is "to articulate possibilities that do not yet exist" (p. 41). Indeed, in Taylor's (1989, 2004) notion of the social imaginary, there are normative patterns of ideation and generalization that, as styles of thought, 
represent a cultural tendency to reason in particular ways. Just as a person born into a language will think in that language and will choose ideas that have already been pre-formed in that language, so a social imaginary has its own internal coherence, and, as with language, there will be a psychological effect in individuals of their being in control, employing culturally embedded concepts as a means of reasoning towards their own ends. As I note elsewhere,

while identifiable as concepts or ideals for a particular place and time, these symbols are not fixed and universal but are driven by personal desires and social-utopian hopes for the world to improve in particular ways. As with all ideals, what is is a fantasy, the ideal being an empty signifier. (Wiebe, in press)

Social discipline, that which makes one subject to the imaginaries of the day, is predominantly psychological, a commitment that can appear to be morally compelling in its support of community, common sense, and shared beliefs. Subjectivity is formed in the public realm, says Pinar (2010). "It very much matters with what and with whom one becomes [a subject]" (p. 3).

In The Birth of Biopolitics, published in English in 2008, Foucault details the emergence of a contemporary social imaginary, a neoliberal style of thought that, as with other social imaginaries, makes individuals complicit in their own subjectivity. Introducing the concept of homo œconomicus, Foucault (2008) argues that distinct from Marx's bourgeois subject is a new entrepreneurial subject who cannot escape the forces of the market economy, since all human activity is defined instrumentally as economic. The distinction is an important one. While Marx's bourgeois subject was a consumer citizen who experienced alienation because of the corporate re-appropriation of human values, what is new is that homo oeconomicus has a selfreasoning that is market-based. Just as the strategies of regulation, marketization, and globalization of economic exchange produce a perception of protecting freedoms, so these same strategies, when applied socially and psychologically, are perceived commonly to be choices people make to further their own interests. The subject, says Foucault, will be an "entrepreneur of himself" (p. 226); principles of market regulation will be self-imposed as technologies of the self. Important to note is the neoliberal construal of personal freedom as an individual's free choice (to exchange goods and services), as well as a conflation of personal freedom with market freedom. Whereas classical liberalism equated economic activity with doing business, neoliberalism defines all human activity as economic. Tracing this distinction to Mises, Gane (2014) is particularly helpful, noting that for the neoliberal subject, "All action is economizing with the means available for the realization of attainable ends. 
The fundamental law of action is the economic principle. Every action is under its sway" (p. 8). When economic activity is no longer exclusive to the transaction of goods and services, economic reasoning is not limited to marketplace application but extends to "domains of behaviour or conduct" (Foucault, 2008, p. 268). Homo oeconomicus is a subject who, in pursuing self-improvement in relation to a social ideal, converts human effort into activities of enterprise and production, enacting a self-discipline in order to achieve particular ends. In this way, neoliberal subjects, such as homo oeconomicus, participate actively and eagerly in their own subjectivity.

If we apply the concept of homo oeconomicus to education, we would expect to find the normalized habits and routines of teachers having underlying economic justifications. Further, a biopolitics of education would mean that a teacher's disciplining of self would apply in pedagogic activity and professional development to the extent that the meaning of an experience would be interpreted only in relation to economically determined institutional goals. The ideal teacher in the neoliberal imaginary would understand teaching as advancing the economic prospects of the next generation, narrowing pedagogic activity to only those means that would achieve the ideal. Williamson's (2013) extensive analysis of curricula in the United Kingdom, the United States, Australia, and Canada suggests that this is indeed the case. He explains how the influence and combination of psychology and computer science on education has created a phenomenon of CompPsy, the shaping of students into "workers for the competitive pressures of economic globalization" (p. 89). What is of concern to Williamson is how what appears to be "personal choice, personal projects, and self-enterprise" (p. 88) is really little more than "self-entrepreneurial behavior... [of] the globalized cultural expression of a set of Silicon Valley cyber libertarian values" (p. 89). CompPsy is the application of a neoliberal social imaginary to education in order to have teachers prepare students to become the neoliberal subjects Foucault identified as homo oeconomicus. The ideal graduates are, in Williamson's (2013) words,

Portfolio people who think and act in terms of their résumé, and who define their own personal projects in entrepreneurial terms as businesses or enterprises... [they are] flexible, interactive, and constructivist learners able to continue learning and adapting, based on constant reflexive self-analysis, right through the life cycle. (p. 96)

While Williamson titles his book, The Future of Curriculum, there is also something historical here-a reductive and instrumental application of curriculum. The reductive and instrumental tendencies of the Tyler Rationale (1949) for planning instruction are particularly illustrative of the predominant metaphor of schooling as a business. 
From lesson plans to policy, and everything in between, what is referred to as curriculum is almost without exception the preplanned document that selects and organizes learner experiences to meet objectives that can be assessed. More than 60 years later, the normative effects of the Tyler Rationale still hinder efforts that promote difference, ambiguity, and doubt. The effect is silence. Lest there be teachers who might otherwise speak, we make heroes of them, conferring on them iconic projections of a social fantasy that cannot endure deviations from the normative ideal.

To summarize the argument so far, in the first part of this essay I have argued that even lovely objectives limit the range of human agency as the planned future forecloses on the present possibility of speaking. Functioning in the social imaginary as desirable, social ideals necessarily create a taken-for-grantedness that inspires selfdiscipline in beliefs, thinking, and practices in order to achieve social-utopian hopes for the world to improve in particular ways. Following the work of Foucault (2008) and Williamson (2013), I have shown that a prevailing social imaginary in education today is neoliberalism, a style of thought that conflates personal freedom with market freedom, defining all human activity as economic. Pursuing self-improvement in relation to a social ideal, teachers and students are thus commended for converting human effort into activities of enterprise and production. Those who discipline themselves in such ways embody the ideal, and I concluded the first section with the claim that the cost of this superhero effect in education is the teacher as a speaking subject. In the remainder of this essay I propose that art, as event, might be a means of restoring voice and agency for teachers. Oriented by Dewey's (1916) definition of education as "the reconstruction or reorganization of experience which adds to the meaning of experience, and which increases ability to direct the course of subsequent experience" (p. 76), I argue that as an event art troubles the strong socialization motif in education and creates intellectual room for genuinely educational moments in schooling.

\section{Art as Event and Agency Through Self-Shattering}

What is educational about education? It is a question of import and urgency, one that Kent den Heyer (2015) has recently asked in response to socialization being the "dominant vision of education today" (p. 3). Following Badiou, den Heyer (2015) proposes "education as event" (p. 3), an "ontological orientation" (p. 19) to education that recognizes how the uniqueness and irreplaceability of each human being can be enacted in a "freedom of subjectification" (p. 10). For den Heyer (2015) this is "the freedom to not only learn a subject, but to become a subject" (p. 8). Pinar (2010) 
provides an extended discussion of what this might look like, and in a close reading of Maxine Greene's (2001) 20 years of lectures at the Lincoln Institute for the Arts in Education, proposes that aesthetic experiences can be "events" of "emancipatory reaggregation" (p. 3). Following Greene (2001), Pinar (2010) notes that the key is "experiencing arts from the inside" since in "undergoing such experience [one] can also break free of one's socially determined location, one's subject position" (p. 2). Understanding art-as-event, he explains, "engender[s] subjective and social reconstruction" (p. 2); in such events the "intensification of experience implies selfshattering insofar as the boundaries of the self dissolve into the aesthetic experience that extricates us from submersion in the banal" (p. 2). If the cost of the superhero effect on education is the teacher's silence, then the price to be paid to regain a sense of agency is self-shattering. The trouble, if I'm reading the contemporary educational landscape accurately, is a persistent social imaginary that the ends (agency, voice) can be achieved through less drastic means. But poststructural theorists have cautioned us not to suppose too easily that we are acting freely and autonomously against a social imaginary.

When we are advancing the case for an education that enhances student agency, it is important not to gloss over the poststructuralist concern of how the power of discourse subjects the self; for teachers this means understanding schooling as part of the cultural hegemony that normalizes dominant modes of thinking and being. In Wittgenstein's (1963) eyes this is precisely the aim of philosophy-to bring to awareness the assumptions behind life's daily activity, to illuminate the ideology underneath language, to show the interplay of function and meaning in language, what he called "language games" (p. 98). Cochran-Smith (2001) writes that in order to "alter the life chances of children," educators must explicitly and deliberately challenge the common practices that are "deeply embedded in systems of schooling and in society" (p. 3). Speaking to Greene's influence on curriculum studies, Miller (2010) says that teachers' "constant obligation [is] to choose to struggle toward [what Greene calls] wide-awakeness" (p. 128). Like Freire (1973), Miller (2010) understands agency as coming to consciousness, and that consciousness is vital to "combatting the curriculum problem" (p. 128) of teaching without understanding the assumptions behind what is being taught.

Regarding agency, two commonplace assumptions in education that are not given enough critique are individual autonomy and knowledge neutrality. In the former assumption, the individual is presumed to be born with the faculties of reason and autonomy, and what follows is the second assumption, that with proper procedure the reasoned individual can make knowledge claims that are without bias. 
Biesta (2007) traces these assumptions back to Kant's universal and ahistorical individual. Following Kant, many have assumed "absolute self-knowledge rather than mere interpretation" (Hurst, 2002, p. 259). As Hurst poignantly explains, Kant "trapped himself into positing a self-consciousness that inhabited a vantage point outside the constitutive activity of consciousness" (p. 259). As Wong notes (2009), "Education characterize[s] ideal students as rational and in control of their thinking and actions. The good student is often described as intentional, cognitive, metacognitive, critical, and reflective.... [This] tradition is deeply rooted in...the story of Western civilization" (p. 192). Because the story of human reason and human autonomy has been so widely embraced, what have followed have been educational endeavors-such as the still influential Tyler Rationale (1949) — that have not accounted for the constitutive activity of consciousness, or the power of discourse and its power relations to constrain consciousness. Not accounting for the former is to create curriculum without attention to difference and diversity, and not accounting for the latter is to create curriculum without attention to privilege and power. In short, since the human subject is not a closed system that can access reason independently for its purposes, how are we to understand agency?

To question the assumptions of human reason and autonomy is a marker of poststructuralist concerns in education. Familiarly referred to as the linguistic turn, with increased skepticism of the human capacity for non-referential reason and autonomy, what has dissolved is faith in how a subject can come to ontological or epistemological knowledge. Hurst (2008) explains it this way: "What happens to metaphysical thinking when the realization dawns that a final cure for the madness of doubting... is not yet found" (p. 113). And more fundamentally, what are we left with when even the capacity by which truth might be found cannot survive "the incursion of language into thinking" (p. 113). Beginning with Wittgenstein's notion of the impossibility of private language, Saussure (1974) argues that the human self cannot autonomously select the best words to convey preconceived ideas (i.e., based on a capacity to reason), but that the self is able only to conceive of ideas because of the language that precedes such a self. The self is thus born into-or constituted inlanguage, and in using language, remains subject to it, that is, becomes a subject since language always remains in excess of the self. This social operation of language is a feature of what is called discourse; when one extends Saussurian logic to the self, what disappears is one's autonomy, the pre-existence of a self who uses language to suit individual purpose, since language disciplines the self into the social norms that language conveys implicitly. 
This being the human condition, the first instance of agency is becoming conscious of one's condition. This is no simple task for if, as Hurst (2008) notes, "[T]here can be no presence or consciousness outside of language which serves as a privileged or ultimate point of reference for the sign ' $I$ '" (p. 121), then the question becomes under what conditions might it be possible to recognize one's condition and struggle against it. In addressing the thorny problem of agency, the disciplines have varied in their approaches as to how the self is constituted from its subjectivity as a subject. Huebner (1966) offers a useful, if sexist, summary.

Release from the confinement of existing language, or more appropriately, transcendence of existing patterns of speech is available through several channels. The theologian would argue that the vicious circle is broken or transcended only by grace, mediated through the openness and reciprocity available through prayer. The aesthetician would argue that literature, specifically poetry, enables lowly man [sic] to break out of his [sic] verbal prison and achieve a "victory over language." The scientist would point to his [sic] success with observation, classification, hypothesis formation, and experimentation as a way of breaking through language barriers. (p. 8)

In emphasizing a few phrases from Huebner (1966), we can see that education for agency ought to involve breaking the vicious cycle, or breaking out of prison, or breaking through barriers. Considering its overt social regulation, schooling is rarely a transformative process during which the self breaks through. Given the structural position teachers have in schools, it is quite difficult for them to act against their regulatory role. Cochran-Smith (2001) writes that teachers need to "teach against the grain" (p. 3), and yet the fear of doing so is very real. Even when teachers begin to recognize the strong regulatory protocols of schooling and show desire to work against them (Joseph, 2007), the fear of rocking the boat is directly tied to employability (Wiebe \& Macdonald, 2013), a legitimate concern that Cochran-Smith (2001) acknowledges, saying that teachers who teach with the grain are likely to be more in demand. Recalling Huebner, because the cycle is vicious, teachers who contribute to student agency will be the exception, rather than the rule. It is at this very point of impossibility, of exceptionality, that an education for student agency might become possible. As noted above, the critical question for such an education is: "Under what conditions might it be possible for one to become conscious of not having agency, but then struggle to gain it?" I believe those conditions are immanent to a teacher's self- shattering via art, or the experience of art-as-event. 
Reviewing Huebner's influence on curriculum, particularly his direct connection to schools, Apple (2010) writes, "The study of curriculum was meant to be not simply 'academic.' It was meant to help us build something" (p. 99). Huebner's (1968) emphasis on building something applies not just to the social world, but also to the self. When it comes to agency, questions of self and the social world belong together. Applied to the student-self, building something is not singularly an investment in the student's socioeconomic benefit, but a construction process that has value to the self's development as a human being.

Developmental self-theories recognize that the self is not fully formed at birth. Understanding self-development as a social process, both Maslow (1968) and Rogers (1951) contend that who we become in the world develops in relation to those others whom we perceive to be in our world. Heidegger (1927/1961), similarly, theorized that in addition to self-formation being a social phenomenon, DaSein (his word for the self as a-being-in-the-world), shares time and space with others, and as a consequence of this shared reality, DaSein, unlike natural objects, experiences time as moving forward. The embodied human self shares physical space in the world with others, but more than that, DaSein is not static. Because we feel time passing, our experience of self is oriented to the world chronologically; we easily look forward and back, compiling a history of who we are and who we could be. In everyday language it is something of an error to think of ourselves as human beings since this misnomer suggests full development or formation. More accurate would be to think of ourselves as human becomings, ever reaching, but always not yet becoming what we can already imagine.

Recalling Freud's concept of Nachtraglachkeit (afterwardsness), Summers (2012) notes that in addition to being situated in time, human beings construe meaning onto the past and the present in relation to the future; the past comes to be reinterpreted from our vantage point on the future. The process is as continuous as our movement into the future. Each tomorrow becomes a yesterday, and tomorrow's tomorrow (and the many tomorrows hence) will come to influence how I categorize and recount the events and circumstances that make up my experience of today.

At the nexus of DaSein and Nachtraglachkeit is the potential of art-as-event. For education to enact this ontological orientation, imaginative work is required. Panayotidis et al. (2015) express that it is a "struggle to articulate possibilities that do not yet exist, where assumed truths and conceptual structures fail to grasp what we experience" (p. 41). Following Rorty's notion of strong poetry, they argue that such struggles are efforts of poiesis, or art-making, producing representations of meaning 
"never used before" (p. 41, emphasis added). This struggle arises from the fact that human subjects will construct the possibility of the future based on the empirical reality they see, and this limits them. What they cannot imagine is not just impossible, but outside the limits of their awareness. For subjects to think beyond the immediacy of empirical perceptions in an everyday educational event, such that even their motives and unconscious feelings are elucidated, is the dilemma of the necessary and impossible task of teaching, of discerning the world of the other in such a way that self-shattering is an agentic process.

The recognition of new ways of being for the subject is a much more subtle process than the commonly advocated pedagogy of caring for a student. A pedagogy of care, while necessary for building a trusting relationship, is not sufficient for attenuating the historical patterns of thinking that operate as immovable truths to constrain what is possible and not possible in a subject's reality. Deconstructing the façade of truth is the process toward what Freire (1973) called conscientization, though there have been some historical differences in the naming. Putting the constitutive onus of consciousness more on the student, Pinar and Grumet (1976) have called this process currere. Greene (1973) saw possibilities of wide awakeness happening when it was the teacher's seeing that mattered: in seeing as strangers teachers were more likely able to see differently from the realities that constrain thought. Later Greene (1995) emphasized the role of imagination in this process. Huebner (1999) called it a transcendent process; Block (2004) a process of prayer; updating earlier work, Pinar (2006) likened it to bildung, and then later to the development of character (2012). Given the slippery nature of language, attempts at clarity and certainty have been synoptic strategies in curriculum, and yet, as Schubert (2010) insightfully points out, every synoptic strategy creates expansion and the need for additional and ongoing expository text.

In addition to the cultural and structural constraints implied in the concept of discourse, the teacher has students who have disempowering and/or limiting patterns of thinking and ways of being, whether from family history, life circumstances, or previous experiences of education. Born into language and culture, students (and teachers) experience additionally formative events that restrict agency, even arrest it. Rather than risking emotional investment in aspirations and becoming genuinely engaged in learning, an easier route for the student-self is compliance learning. This is what Freire (1973) called the banking model of education in which deposits are made into a student's mind irrespective of meaning, purpose, or personal growth. Compliance learning is not so much deliberate resistance to the personal growth that learning ought to require, but, rather, more of the learned cultural pattern that fosters the belief that learning can happen without growth. Compliance learning 
is still learning, but, like a cancerous cell, it simply attacks healthier kinds of learning that advance student agency. Such learning is similar to conflict-avoidance strategies that are a self's ineffective means of genuinely trying to maintain a relationship in that it, too, deteriorates and becomes simply a matter of compliance when both students and teachers are able to satisfy systemic requirements even while avoiding the necessary tensions that come with personal investment, long-term commitment, or daily engagement.

Where there is compliance learning, a passionate engagement in the arts can sometimes shatter what has become solidified. Through art is the possibility of "reflective engagement" and "subjective reconstruction" (Pinar, 2010, p. 5). Regardless of discipline, and prompted by the passionate curiosities that advance the disciplines, art-as-event involves imagining the world other than it is. Through art-as-event the subject experiences difference from the normative effects of schooling that create compliance.

Dewey (1902) located education not just within the student's experiences, but also within the student's physical being. For Schubert (2010), from the embodied relationship of student and curriculum, we learn "what is worth needing, doing, being, becoming, overcoming, sharing, contributing, wondering, and more" (p. 21). Critical to this process is the teacher's ability to perceive and appreciate what is not yet visible, including seeing past opposition, defensiveness, and compliance. Following Pinar (2010), I emphasize art-as-event because a curriculum that flows from this does not impose a specific agenda, but is an open-ended exploration in which students feel a personal connection to their learning. Bringing his clinical experience at the Feinberg School of Medicine to bear on Heidegger's rendering of ekstatic (the possibility of encountering other beings), Summers (2012), points out that "[the] dispositional affects, desires, and passions that emerge when defenses give way provide clues to unformed possibilities that can become ways of being if perceived as such" (p. 236). What is striking in Summers' wording is the similarity to Freire's (1998) description of authentic dialogue among teachers and learners in a culture circle. Akin to "defenses giving way" (p. 236), Freire speaks of the necessity of students becoming the knowledge producers (to the same degree of legitimacy as the teachers), and only insofar as there is this shifting (and sharing) of roles can students become "thinking subjects" (p. 89) and find meaning in their learning. Freire's thinking subject is one who becomes conscious of the normative structures in culture, and who-no longer a compliant learner-then takes action. Like Summers, Freire sees this, potentially, as a new way of being, or, in Pinar's (2010) terms, an "emancipatory reaggregation" (p. 3). 
Central to the ongoing myth of human autonomy and reason, agency is too often assumed. Contemporary competencies-based curriculum guides, for example, uncritically presume agency with their primary focus being the selection, scope, and sequence of outcomes. With only token reference to difference and diversity, it is a homogenous student who is presumed, and who will, no doubt, achieve the outcomes through good teaching and, sometimes optional on the student's part, hard work. ${ }^{2}$ Completely unaccounted for are the normative effects of schooling.

Teaching for student agency means acknowledging the normative effects of schooling so that students can come to understand more about the reality of their dayto-day lives. There is a productive tension here, one where agency can seem impossible, and yet is made possible by a teacher's refusal to foreclose on a student's potential. At the threshold of im/possible agency, teachers and students might acknowledge both the constraining force of discourse on the self, and despite that condition, still strive for a kind of interaction that is empowering. According to Ayers (2010),

[i]f society cannot be changed under any circumstances, if there is nothing to be done, not even small and humble gestures toward something better, well, that about ends all conversation. Our sense of agency shrinks, our choices diminish. What more is there to say? But if a fairer, saner, and more just social order is both desirable and possible, that is, if some of us can join one another to imagine and build a participatory movement for justice, a public space for the enactment of democratic dreams, our field opens slightly. (p. 8)

Education that is person-centred and socially empowering is not a new idea. Dewey (1938/1997) put the student's experience at the heart of education. While not new, prioritizing the student in times of global expansion can seem nostalgic, naïve, or even sentimental. In times of neoliberal policy-making, it can often seem as though there is a crisis in education. The creation of crisis enables a strict focus on core curriculum, often packaged as 21st century skills; these being the only way to return to economic prosperity. We know that the popular socio-economic imagination has direct influence on the actions and decisions of day-to-day life in the classroom (Weis \& Fine, 2012), and we know that the contemporary preference for prioritizing education as a future-oriented endeavour leads to rhetoric such as investment and returns where the return on the investment of public education occurs when students gain significant employment and become taxpayers. The trouble with this approach to education is a curriculum that predefines the world students will enter: as a result, students and teachers become valuable only in relation to their outcome demonstration, 
that is, their return on investment. Those with minimal returns are routed out of the system by its own regulatory safeguards. At the micro level, while there might be school spirit and collegiality for some, an instrumental educational philosophy cannot help but dehumanize the participants.

As I argue with Morrison-Robinson, focusing education on employment leaves schools and society vulnerable "to an unbalanced neo-liberal capitalization of being human" (Wiebe \& Morrison-Robinson, 2013, p. 6). This unbalanced imagination of an always better self (meant to compete with others from elsewhere) forecloses on the process of becoming human. Through aesthetic experiences, how the self imagines its potential can be freed from the cultural norms that subjugate it, particularly those norms that gain their power from the employment motif. Having agency depends on being able to imagine differently, on having an alternative vision to that prescribed by social norms. Given these dark times, it is entirely possible that teachers regularly align with this norming process, choosing the comfort and fantasy of being society's superheroes.

\section{Notes}

1. See Pinar (2006) for an extended discussion of Bildung in Europe and North America.

2. This illogical position is unfortunately gaining traction with the tight coupling of teaching and learning, so much so that the political message seems to construe teaching as a necessary and sufficient cause of learning. This position is probably best exemplified in the populist call to pay teachers according to students' results. In Canada, Clifton's (2013) specious literature review, funded by the Fraser Institute, has recently received press in the Globe and Mail (see Alphonso, 2013). 


\section{References}

Alphonso, C. (2013, September 9). Teachers should be paid according to student performance, Fraser Institute says. Globe and Mail, n.p. Retrieved from http://license. icopyright.net/3.8425?icx_id=14191465

Apple, M. (2010). Fly and the fly bottle: On Dwayne Huebner, the uses of language, and the nature of the curriculum field. Curriculum Inquiry, 40(1), 95-103.

Ayers, W. (2010). Teaching in and for democracy. Curriculum and Teaching Dialogue, 12(2), 3-10.

Biesta, G. (2007). Foundations of democratic education: Kant, Dewey, Arendt. In R. van der Veen, D. Wildemeersch, J. Youngblood, \& V. Marsick (Eds.), Democratic practices as learning opportunities (pp. 7-18). Rotterdam, Holland: Sense.

Block, A. (2004). Talmud, curriculum and the practical: Joseph Schwab and the Rabbis. New York: Peter Lang.

Block, A. (2014). Hey, I'm no superman: The teacher as hero. (1), 30-45.

Clifton, R. (2013). Obtaining better teachers for Canadian public schools: A review of the "teacher effectiveness" research literature. Retrieved from http://www.fraserinstitute. org

Cochran-Smith, M. (2001). Learning to teach against the (new) grain. Journal of Teacher Education, 52(1), 3-4. doi:10.1177/ 0022487101052001001

den Heyer, K. (2015). An analysis of aims and the educational "event." Canadian Journal of Education, 38(1), 1-27.

Dewey, J. (1902). The child and the curriculum. Chicago: University of Chicago Press.

Dewey, J. (1916). Democracy and education. New York: Macmillan.

Dewey, J. (1997). Experience and education. New York: Touchstone. (Original work published 1938)
Foucault, M. (2008) The birth of biopolitics: Lectures at the Collège de France, 1978-9 (G. Basingstoke, Trans). London: Palgrave Macmillan.

Freire, P. (1973). Education for critical consciousness. New York: Continuum.

Freire, P. (1998). Teachers as cultural workers: Letters to those who dare. Oxford, CO: Westview Press.

Gane, N. (2014). The emergence of neoliberalism: Thinking through and beyond Michel Foucault's lectures on biopolitics. Theory Culture Society, 31(4), 3-27. doi:10.1177/0263276413506944

Greene, M. (1973). Teacher as stranger. New York: Wadsworth.

Greene, M. (1995). Releasing the imagination. San Francisco: Jossey-Bass.

Greene, M. (2001). Variations on a blue guitar: The Lincoln Center Institute Lectures on aesthetic education. New York: Teachers College Press.

Heidegger, M. (1961). Being and time. (F. D. Wieck \& J.G. Gray, Trans). New York: Harper \& Row. (Original work published 1927)

Huebner, D. (1966). Curricular language and classroom meanings. In J. B. Macdonald \& R. Leeper (Eds.), Language and meaning (pp. 8-26). Washington, DC: Association for Supervision and Curriculum Development.

Huebner, D. (1968). Implications of psychological thought for the curriculum. In G. Unruh \& R. Leeper (Eds.), Influences in curriculum change (pp. 28-37). Washington, DC: Association for Supervision and Curriculum Development.

Huebner, D. (1999). The lure of the transcendent: Collected essays by Dwayne Huebner. Mahwah, NJ: Erlbaum.

Hurst, A. (2002). Self formation and the speculative: Gadamer and Lacan. South African Journal of Philosophy, 21(4), 258-273. 
Hurst, A. (2008). The impotence of pseudoantagonism: A Derridean response to Zižek's charge of practical irrelevance. South African Journal of Philosophy, 27(1), 110-126.

Joseph, P. B. (2007). Seeing as strangers: Teachers' investigations of lived curriculum. Journal of Curriculum Studies, 39(3), 283-302.

MacDonald, R., Wiebe, S., Goslin, K, Doiron, R., \& MacDonald, C. (2010). The workload and worklife of Prince Edward Island teachers. Charlottetown, PE: PEI Teachers Federation.

Maslow, A. (1968). Toward a psychology of being. New York: Wiley.

Miller, J. (2010). Curriculum as a consciousness of possibilities. Curriculum Inquiry, 40(1), 125-141.

Ng-A-Fook, N. (2014). Spinning curriculum designs at a crossroads: Big ideas, conversations, and reconciliation. Journal of the Canadian Association for Curriculum Studies, 12(1), 97-118.

Panayotidis, L., Towers, J., Lund, D., \& Smits, H. (2015) Collaborative writing as an exercise of poetic resistance in teacher education. Journal of the Canadian Association for Curriculum Studies, 12(2), 37-65.

Pinar, W. F. (2006). Bildung and the internationalization of curriculum studies. Transnational Curriculum Inquiry 3(2). Retrieved from http://ojs.library.ubc.ca/index.php/tci/ issue/view/13

Pinar, W. F. (2008). Introduction to a common countenance. Journal of the Canadian Association for Curriculum Studies, 6(2), 129-155.

Pinar, W. F. (2010). Notes on a blue guitar. Journal of Educational Controversy, 5(1), 1-9. Retrieved from http://cedar.wwu.edu/jec/ vol5/iss $1 / 18$

Pinar, W. F. (2012). The character of curriculum studies: Bildung, currere, and the recurring question of the subject. New York: Palgrave Macmillan.

Pinar, W. F., \& Grumet, M. R. (1976). Toward a poor curriculum. Dubuque, IA: Kendall/Hunt.
Rogers, C. (1951). On becoming a person. Boston: Houghton Mifflin.

Saussure, R. (1974). Course in general linguistics. Toronto, ON: McGraw-Hill.

Schubert, W. (2010). Journeys of expansion and synopsis: Tensions in books that shaped curriculum inquiry, 1968present. Curriculum Inquiry, 40(1), 17-94. doi:10.1111/j.1467-873X.2009.00468.x

Summers, F. (2012). The transcendent experience of the other: Futurity in empathy. Journal of Theoretical and Philosophical Psychology, 32(4), 236-245.

Taylor, C. (1989). Sources of the self. The making of the modern identity. Cambridge, MA: Cambridge University Press.

Taylor, C. (2004). Modern social imaginaries. Durham, NC: Duke University Press.

Tyler, R. (1949). Basic principles of curriculum and instruction. Chicago: University of Chicago Press.

Weis, L., \& Fine, M. (2012). Critical bifocality and circuits of privilege: Expanding critical ethnographic theory and design. Harvard Educational Review, 82(2), 173-201.

Wiebe, S. (in press). Decoupling creativity and innovation: A historical hack at the roots of neoliberalism and systems thinking in education. In N. Ng-A-Fook, S. Pratt, B. Smith, \& L. Radford [Eds.], Hacking education in a digital age: Teacher education, curriculum, and literacies.

Wiebe, S., \& Gard, L. (in press). Curriculum studies in Atlantic Canada, Charlottetown, PE; Island Studies Press.

Wiebe, S., \& MacDonald, C. (2013). Passion and recognition in teacher's worklives. In $\mathrm{E}$. Lyle \& J.G. Knowles (Eds.), Bridging theory and practice: Pedagogical enactment for socially just education (pp. 279-301). Toronto: Backalong Books.

Wiebe, S., \& MacDonald, C. (2014). Intensification and complexity in teachers' narrated worklives. Canadian Journal of Education, 37(4), $1-26$. 
Wiebe, S., \& Morrison-Robinson, D. (2013). Becoming $a / r /$ tographers while contesting rationalist discourses of work. MultiDisciplinary Research in the Arts, 3(2), 1-18.

Williamson, B. (2013). The future of curriculum. School knowledge in a digital age. Cambridge, Mass: MIT Press.
Wittgenstein, L. (1963). Philosophical investigations. (G.E.M. Anscome, Trans). Oxford: Blackwell \& Mott.

Wong, D. (2009). Beyond control and rationality: Dewey, aesthetics, motivation, and educative experiences. Teachers College Record, 109(1), 192-220.

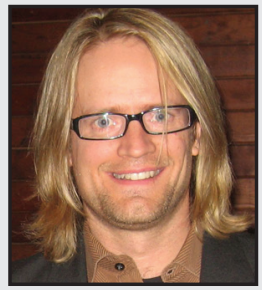

Sean Wiebe lives in Charlottetown and is an Associate Professor of Education at the University of Prince Edward Island. His research interests include curriculum studies, narrative research, poetic inquiry, and $a / r /$ tography. For the last four years he has been the principal investigator for the Digital Economy Research Team, investigating connections between new literacies and the digital economy. Recent publications appear in the Canadian Journal of Education and Language and Literacies Education. 